\title{
Temperature-dependent interactions between hydrophobically modified ethyl(hydroxyethyl)cellulose and methyl nanocellulose
}

\author{
Johanna Lyytikäinen (D) Teija Laukala • Kaj Backfolk
}

Received: 5 February 2019/Accepted: 26 June 2019/Published online: 11 July 2019

(C) The Author(s) 2019

\begin{abstract}
The temperature-dependent association between methyl nanocellulose and hydrophobically modified ethyl(hydroxyethyl)cellulose (EHEC) was determined. Methyl nanocellulose was mixed under different concentrations with EHEC in aqueous media. The hydrophobic association, cloud point and temperature-dependent flocculation were studied using turbidity, rheometry and laser diffraction analysis. The phase separation of EHEC samples containing different amounts of methyl nanocellulose in $1.0 \mathrm{wt} \%$ solution was measured between 20 and $70{ }^{\circ} \mathrm{C}$, showing that the cloud point of the solutions increased with increasing nanocellulose content. An increase in the low shear viscosity and gelation behavior of the mixture with the highest methyl nanocellulose content in conjunction with changes in cloud point indicated that the hydrophobic nanocellulose strengthened the hydrophobic association and the gel network. A bimodal particle size distribution was observed for
\end{abstract}

J. Lyytikäinen $(\bowtie) \cdot T$. Laukala $\cdot$ K. Backfolk

School of Energy Systems, Packaging Technology, LUT

University, P.O. Box 20, 53851 Lappeenranta, Finland

e-mail: Johanna.Lyytikainen@lut.fi

T. Laukala

e-mail: Teija.Laukala@lut.fi

K. Backfolk

e-mail: Kaj.Backfolk@lut.fi

K. Backfolk

Stora Enso Oyj, 55800 Imatra, Finland both the pure EHEC and hydrophobically modified nanocellulose reference solutions, whereas the mixture had a trimodal particle size distribution when being diluted. The colloidal stability and re-structuring mechanism of the dilute methyl nanocellulose suspension after shear and the role of birefringence are discussed.

Keywords Gel $\cdot$ Hydrophobically modified ethyl(hydroxyethyl)cellulose · Methyl nanocellulose · Phase separation $\cdot$ Rheology

\section{Introduction}

Water-soluble cellulose derivatives can be modified with hydrophobic groups in order to provide characteristic features in various formulations such as paints, inks, cosmetics, food and personal care products. In the case of cellulose derivatives such as ethyl(hydroxyethyl)cellulose (EHEC), a small amount of branched hydrophobic side groups are grafted to the cellulosic backbone (Thuresson and Lindman 1997). Through modification of the level and position of the hydrophobic groups, temperature-dependent solubility and selfassociative behavior can be controlled. Various published articles have shown the role of the interaction between polymer and surfactant where micellar-like aggregation occurs via hydrophobic groups 
(Kjøniksen et al. 1998; Nyström et al. 1996; Thuresson and Lindman 1997). The level of surfactant addition has a strong influence on the rheological properties (Thuresson and Lindman 1997; Nyström et al. 1995) as well as, for example, type of surfactants and total solid of the system. The addition of anionic surfactant to hydrophobically modified EHEC first increases the solid-like behavior in the solution until it achieves a maximum value and then starts to decrease (Piculell et al. 1996).

The association between EHEC and surfactants has been determined with cloud point measurements. When the EHEC solution is heated it starts to separate at a certain temperature into polymer-rich and polymer-poor phases and becomes cloudy (Carlsson et al. 1986; Joabsson et al. 1998; Khuman et al. 2014). It is known that the concentration and type of electrolyte affect the cloud point of EHEC. Addition of sodium chloride $(\mathrm{NaCl})$, for example, reduces the solubility of EHEC and hence lowers the cloud point. $\mathrm{NaCl}$ facilitates the phase separation since it makes the solution more polar, and hydrophobic interactions become stronger. (Carlsson et al. 1986; Khuman et al. 2014; Nyström et al. 1996).

Thermoresponsive methylcellulose is a cellulose derivative, which gels at elevated temperatures but has a good solubility in water at lower temperatures (Arvidson et al. 2013; Kamitakahara et al. 2008). The concentration and especially the heating rate affect the gelation of the methylcellulose. Higher methylcellulose concentrations reduce the gelation and cloud point temperatures and a lower heating rate lowers the gelation temperature. (Arvidson et al. 2013). In general, the mechanism of gel formation of methylcellulose is not well understood. One hypothesis is that in aqueous solution the polymer is surrounded by water molecules and that at an elevated temperature the hydrogen bonds become weaker, which facilitates the aggregation of hydrophobic groups in the polymer (Fairclough et al. 2012). One explanation for this behavior could be the self- association of amphiphilic parts in the polymer. (Kamitakahara et al. 2008).

In addition to the widely studied EHEC-surfactant interactions, the various interactions between nanocellulose and surfactants have been studied to some extent (Tardy et al. 2017). Binding between methylcellulose and cellulose nanocrystals (CNC) was studied with a fixed amount of methylcellulose and with an increasing amount of CNC by McKee et al. (2014).
The CNC concentration was found to affect the gel stiffness (McKee et al. 2014). However, there is a lack of understanding of the temperature-dependent interaction between hydrophobic nanocellulose and hydrophobically modified cellulose derivatives. Especially cellulose nanocrystals are known to self-associate and exhibit either isotropic or liquid crystalline behavior dependent on the solid concentration (Orts et al. 1998), which might be due to the fact that cellulose itself, however, has an inherent hydrophobic character where hydrophobic groups can interact (Tardy et al. 2017).

The aim of this study was to investigate the interaction between hydrophobically modified ethyl(hydroxyethyl)cellulose and nanocellulose prepared from methylcellulose. Both polymers are thermoresponsive. In addition to the temperaturedependence, the role of electrolyte concentration on the interactions were determined. Phase separation behavior was determined using cloud point and a rheometer operated in a bob-cup mode. In addition, the particle size and shear-stability of the dilute suspensions were determined in order to confirm flocculation and associate interactions.

\section{Materials and methods}

Aqueous solutions were prepared having different concentrations and ratios of non-ionic hydrophobically modified ethyl(hydroxyethyl)cellulose, EHEC (Bermocoll EHM 200, AkzoNobel Functional Chemicals AB, Sweden) and methyl nanocellulose (MeCellosic acid (MCA), Innotech Materials LLC, United States). Methyl nanocellulose is prepared from methylcellulose through catalytic oxidation (Jin 2017). The salt content of EHEC was max. $4.5 \mathrm{wt} \%$ according to the supplier. $1 \mathrm{wt} \%$ solutions were prepared in distilled water to an ionic strength of $0.01 \mathrm{M}$ sodium chloride $(\mathrm{NaCl}$, Merck KGaA, Germany) using different ratios of nanocellulose and EHEC.

The cloud point was detected visually and the change in turbidity measured using a turbidimeter (Hach 2100AN IS Turbidimeter) for $1 \mathrm{wt} \%$ solutions. The suspensions were heated from 20 to $70{ }^{\circ} \mathrm{C}$ in sealed glass tubes using a water bath at a heating rate of $0.5{ }^{\circ} \mathrm{C} / \mathrm{min}$ and equilibrated at each temperature (Kjøniksen et al. 1998; Olsson et al. 2005). In addition, 
solutions were heated above the cloud point until separation into two separate phases occurred, the phase separation being detected visually.

Viscosity and oscillatory measurements were conducted with a Modular Compact Rheometer (MCR 302, Anton Paar) operated in bob and cup mode using the standardized CC27 measurement cylinder. For the temperature-dependent behavior, the viscosities were measured by heating the solution from 20 to $70{ }^{\circ} \mathrm{C}$ and using a shear rate of $50 \mathrm{~s}^{-1}$ at a heating rate of $0.5^{\circ} \mathrm{C} /$ min. Temperature-dependent viscoelastic behavior was determined under constant shear conditions, at an angular frequency, $\omega$, of $5 \mathrm{rad} / \mathrm{s}$ and a strain amplitude, $\gamma$, of $1 \%$. The shear rate was $50 \mathrm{~s}^{-1}$ and the heating rate $0.5{ }^{\circ} \mathrm{C} / \mathrm{min}$. Before the oscillatory measurements, the linear viscoelastic range was determined with amplitude sweep measurements to ensure that the selected amplitude is in the linear viscoelastic region in the frequency sweeps. A covering plate was used to avoid evaporation at elevated temperatures.

The particle size of the samples were measured using a Zetasizer ZS Nano (Malvern Instruments Ltd, UK), equipped with HeNe gas laser (633 nm). Laser doppler velocimetry (LDV) was used to determine the electrophoretic mobility while the zeta potentials were calculated from the measured electrophoretic mobility using Henry equation with Smoluchowski approximation.

The particle size and stability were determined using dynamic light scattering (DLS). The samples were diluted to a concentration of $0.4 \mathrm{wt} \%$. Measurements were performed at a temperature of $25{ }^{\circ} \mathrm{C}$. The samples were diluted which could influence the concentration-dependent interaction between the nanocellulose and EHEC. The nanocellulose, however, required a higher concentration than EHEC for a sufficient backscatter signal, and this resulted in different measuring concentrations for the different samples. Two different sample preparation procedures were applied.

A dilution-stirring procedure was applied to break the flock or agglomerates. The dilution-stirring procedure consisted of five minutes stirring with a magnetic stirrer, followed by dilution and a further stirring for five minutes. The sample was then diluted again to the desired measurement concentration and the sample was stirred for two minutes at $1300 \mathrm{rpm}$. The measurement immediately after stirring included $60 \mathrm{~s}$ stabilization time in the measurement cell. Five parallel measurements were made to determine the particle size and size distribution at $25^{\circ} \mathrm{C}$, using concentrations of $0.4 ; 0.08 ; 0.06 ; 0.05$ and $0.04 \mathrm{wt} \%$ for Me100, E25:Me75, E50:Me50, E75:Me25 and E100, respectively. The different concentrations were selected in order to ensure a suitable detection signal.

After the initial cycle of mixing and dilution, a second set of particle size measurements was made on a sample at rest using a procedure that allowed ca. 20 min resting time prior to the first measurement. During this time the sample was stabilized to $20{ }^{\circ} \mathrm{C}$. The particle sizes were measured at temperatures of $20,25,30,40,50$ and $60{ }^{\circ} \mathrm{C}$ by applying subsequent heating. Five parallel measurements were made at each temperature. A heating rate of approximately $0.5{ }^{\circ} \mathrm{C} / \mathrm{min}$ was used. After the heating series was completed, the sample chamber temperature was set to $20{ }^{\circ} \mathrm{C}$ and the particle size was measured after $2 \mathrm{~h}$ of stabilization. For each sample, two parallel measurement series were run.

\section{Results}

Cloud point determinations of the $1.0 \mathrm{wt} \%$ EHECmethyl nanocellulose solutions were conducted visually and the change in turbidity was determined with turbidity measurements. The pure and transparent EHEC solution turned from clear to cloudy already at 25-30 ${ }^{\circ} \mathrm{C}$ revealing a relatively low cloud point for EHEC (Fig. 1). The initial turbidity of EHEC was 20 NTU, which decreased with increasing methyl nanocellulose content in the EHEC-methyl nanocellulose mixtures. The addition of methyl nanocellulose increased the cloud point, whereas an increase in solid content from 0.25 to $1.0 \mathrm{wt} \%$ lowered the cloud point for the pure EHEC and methyl nanocellulose solutions. At dilute concentrations, the cloud point of EHEC decreases significantly with increasing concentration, which indicates an increased interaction between the polymers (Joabsson et al. 1998). The turbidity of the EHEC-methyl nanocellulose compositions increased when the solution was heated to $25{ }^{\circ} \mathrm{C}$, but then the decreased until the temperature reached $40{ }^{\circ} \mathrm{C}$ and the started to increase again. The turbidity of the methyl nanocellulose solution remained unchanged until the solution became cloudy, after which the turbidity started to increase rapidly. 
Fig. 1 Turbidity and the cloud point temperatures of the EHEC-methyl nanocellulose solutions. $\mathrm{E}$ denotes EHEC, Me methyl nanocellulose. Squares and dots represent the cloud points of EHEC and pure methyl nanocellulose, respectively

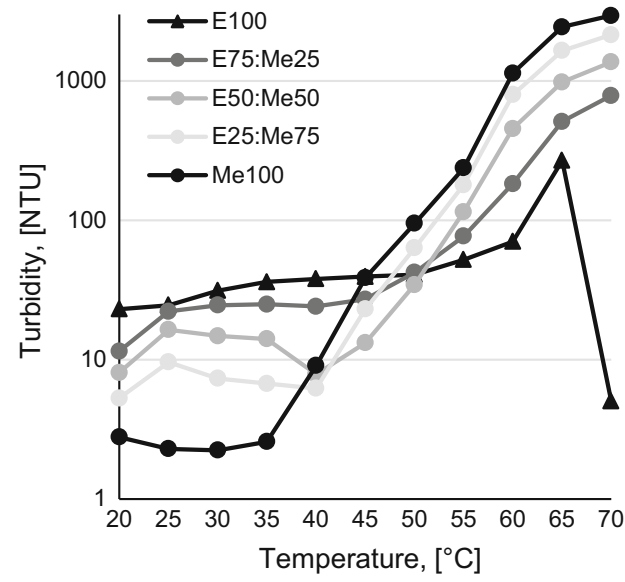

At $20{ }^{\circ} \mathrm{C}$ all the EHEC-methyl nanocellulose compositions were perfectly clear and transparent, but at $35{ }^{\circ} \mathrm{C}$ the pure EHEC and the E75:M25 solution were cloudy (Fig. 2). The pure EHEC solution became cloudy already at $25{ }^{\circ} \mathrm{C}$ and the E75:Me25 solution at $30{ }^{\circ} \mathrm{C}$ as shown in Fig. 1. When the temperature increased to $45{ }^{\circ} \mathrm{C}$, small flocs or particles were seen in the E50:Me50 and in the E25:Me75 solution, but the floc size was smaller in the E25:Me75 solution.
Similar flocs were seen in the E75:M25 solution at $55{ }^{\circ} \mathrm{C}$. It was noticed that when the solution reached the cloud point temperature, the turbidity started to increase rapidly in the nanocellulose-containing samples. No macromolecular phase separation occurred in the methyl nanocellulose-containing solutions at $70{ }^{\circ} \mathrm{C}$.

It was noticed that the addition of methyl nanocellulose increased the cloud point. According to the
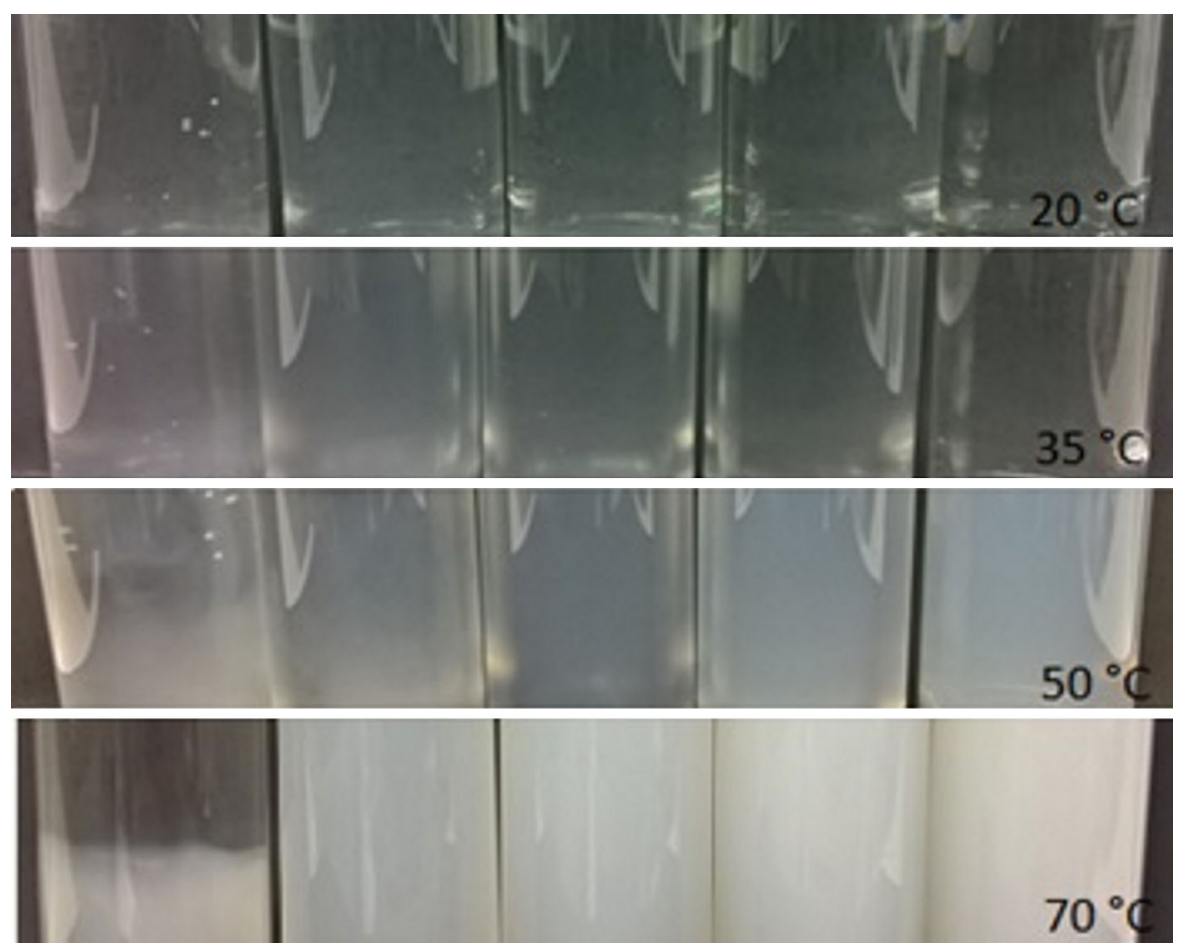

Fig. 2 Phase separation of the EHEC-methyl nanocellulose solutions. Samples from the left EHEC100, EHEC75:Me25, EHEC50:Me50, EHEC25:Me75, Me100 
literature, association between EHEC and anionic surfactants changes the phase behavior and cloud point increases when the degree of surfactant binding is high, while a lower degree of surfactant binding reduces the cloud point (Thuresson et al. 1995; Olsson et al. 2005). In addition, it is known that a high concentration of $\mathrm{NaCl}$ decreases the cloud point. $\mathrm{pH}$ of EHEC solution varied between 5.1 and 5.4 when heated from 20 to $70{ }^{\circ} \mathrm{C}$. The corresponding change in $\mathrm{pH}$ measured for methyl nanocellulose was from 3.2 to 2.8. At these $\mathrm{pH}$ values the electrophoretic mobility was -0.04 for EHEC and between -0.04 and $-0.05 \mu \mathrm{mcm} / \mathrm{Vs}$ for methyl nanocellulose and zeta potential -0.5 for EHEC and between -0.5 and $-0.7 \mathrm{mV}$ for methyl nanocellulose, thus confirming that they are both non-ionic or very weakly anionically charged.

Figure 3 shows the gel behavior and the changes in network structure of EHEC-nanocellulose compositions determined by viscosity measurements. The viscosity of the pure EHEC solution decreased with increasing temperature. EHEC-methyl nanocellulose mixtures had a lower viscosity than the pure EHEC solution at a given solids content, which is simply explained by the lower viscosity enhancing effect of methyl nanocellulose. Gelation of the pure methyl nanocellulose solution starts at $48{ }^{\circ} \mathrm{C}$ while the gelation temperature of the EHEC-methyl nanocellulose composition E75:Me25 starts at $58{ }^{\circ} \mathrm{C}$. The

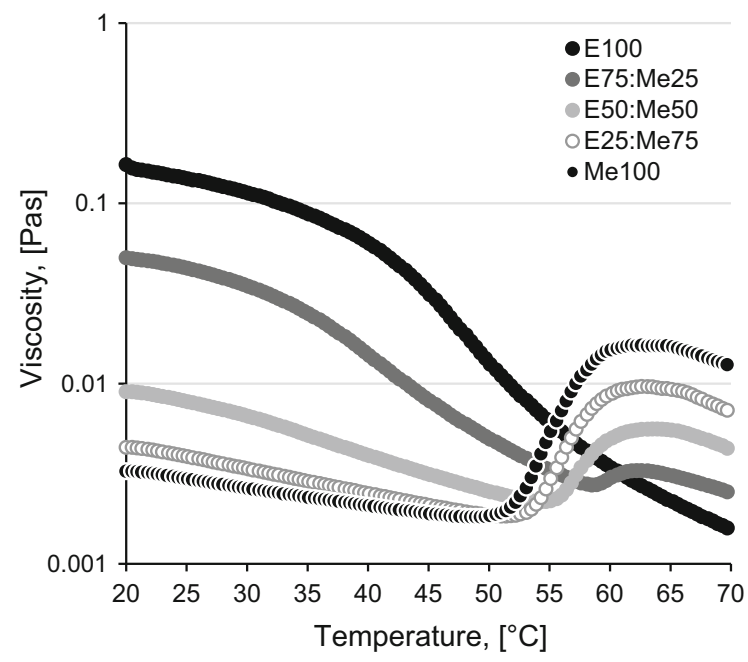

Fig. 3 Viscosity and gelation temperatures of EHEC-methyl nanocellulose mixtures in the $20-70{ }^{\circ} \mathrm{C}$ temperature range with the heating rate of $0.5^{\circ} \mathrm{C} / \mathrm{min}$ gelation temperature determined from the point where the viscosity is at a minimum shows that gelation is more pronounced with a higher methyl nanocellulose content. This behavior with increasing concentration of methyl nanocellulose is partly due to an associate interaction (Lott et al. 2013).

The gelation temperature of the E25:Me75 solution is two degrees lower than of the $0.75 \mathrm{wt} \%$ methyl nanocellulose solution (Fig. 3), but other compositions had gelation temperatures similar to pure methylcellulose solutions. In addition, the initial viscosity of E25:Me75 was higher than that of the pure $0.25 \mathrm{wt} \%$ EHEC solution, which indicates that there is an interaction between EHEC and methyl nanocellulose, since a similar viscosity increase has been observed when anionic surfactant is added to an EHEC solution (Piculell et al. 1996).

Figure 4 shows the temperature dependence of the viscosity determined at different concentrations. The gelation temperature of pure methylcellulose decreased when the concentration increased. Methyl nanocellulose showed a clear thickening effect when the solution entered the gel phase, and this was also observed with the EHEC-methyl nanocellulose mixtures.

The temperature-dependent viscoelastic behavior of the EHEC-methyl nanocellulose mixtures is seen in Fig. 5. At $1 \%$ strain and $5 \mathrm{rad} / \mathrm{s}$ frequency, the EHEC solution shows liquid-like behavior in the studied temperature range as the loss modulus G' is higher than the storage modulus $G^{\prime}$, but when the temperature reached $58{ }^{\circ} \mathrm{C}$, the solution showed only loss modulus. With samples E75:Me25 and E50:Me50, only G', values were detected until the temperature reached $43-45{ }^{\circ} \mathrm{C}$, which is the point where gelation starts, i.e. where $\mathrm{G}^{\prime}=\mathrm{G}^{\prime}$ '. Above the gel point, solutions have an elastic structure where G' is higher than G' corresponding to $61{ }^{\circ} \mathrm{C}$ for E75:Me25 and to $57{ }^{\circ} \mathrm{C}$ for E50:M50. G' increases rapidly with increased temperature and the ratio $G^{\prime}: G^{\prime}$ ' becomes larger indicating, that the structure is more gel-like and stiffer. The decrease in $\tan \delta\left(=G^{\prime} \prime / G^{\prime}\right)$ value confirms that the solution becomes more elastic. Pure methyl nanocellulose and the solution containing 75\% methyl nanocellulose behaved similarly and showed only liquid-like behavior until $57-58{ }^{\circ} \mathrm{C}$, where both solutions have a gel point and an elastic structure, but the $\tan \delta$ value shows that the E25:Me75 mixture is 
Fig. 4 Temperaturedependent viscosity behavior of pure methyl nanocellulose $(\mathrm{Me})$ and EHEC (E) at different concentrations
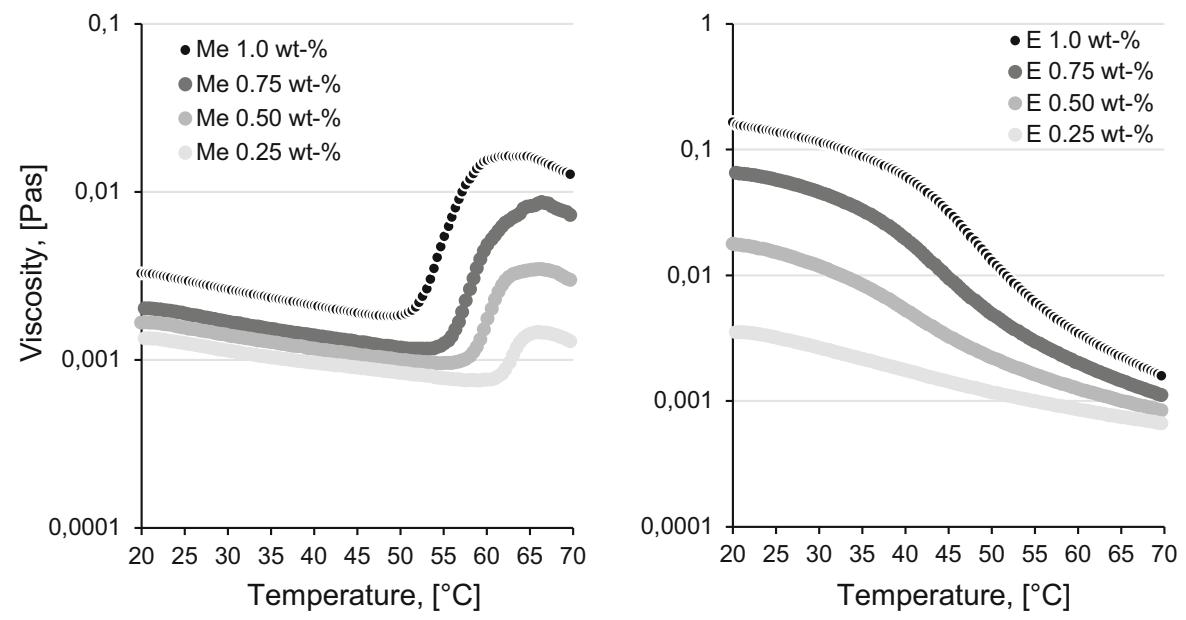

Fig. 5 The behavior with increasing temperature of EHEC and methyl nanocellulose mixtures at $1 \%$ strain and $5 \mathrm{rad} / \mathrm{s}$ frequency. Lines represent the G', values

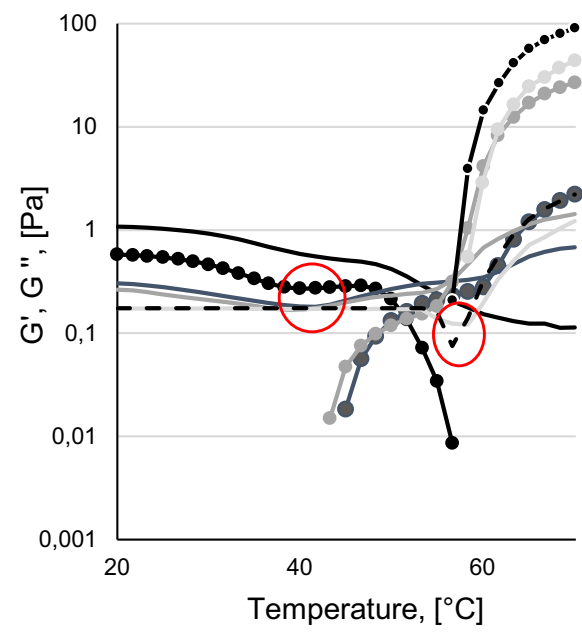

more elastic than pure methyl nanocellulose when the solution reaches the gel point temperature.

The storage modulus of E25:Me75 and of the pure methyl nanocellulose solution remained unchanged when the solutions were heated to 58 and $57^{\circ} \mathrm{C}$, respectively, where the solutions have their gel point and where a simultaneous drop in loss modulus was seen. The loss modulus of solutions containing methyl nanocellulose decreased until the temperature reached $40{ }^{\circ} \mathrm{C}$. With E75:Me25 and E50:M50 this indicates the beginning of the sol-gel transition while the storage modulus was seen $3{ }^{\circ} \mathrm{C}$ higher. The $\mathrm{G}^{\prime}$ value of the EHEC solution also decreased up to $40{ }^{\circ} \mathrm{C}$. A similar behavior was seen in turbidity measurements with all the EHEC-methyl nanocellulose mixtures.

Higher methyl nanocellulose concentrations gave lower gelation temperatures. The difference in gelation temperature between pure and blended solution containing $75 \%$ methyl nanocellulose was $0.5{ }^{\circ} \mathrm{C}$. The $\tan \delta$ value showed that the increase in methyl nanocellulose content increased the ratio of $G^{\prime}: G^{\prime}$ ' rapidly which is characteristic of temperature-responsive gels. The sharp drop in G" value before the gelation starts, which is characteristic of hydroxypropylmethylcellulose (Fairclough et al. 2012), has not been observed for methylcellulose solutions (Fairclough et al. 2012).

The particle sizes of the samples determined at rest and for pre-agitated samples differed for all cases, see Fig. 6. The difference was associated with the formation of weak flocs breakable by stirring. More significantly, the floc forming and floc association of the EHEC differed from those of the nanocellulose. The particle size of the EHEC sample was $60 \%$ greater 


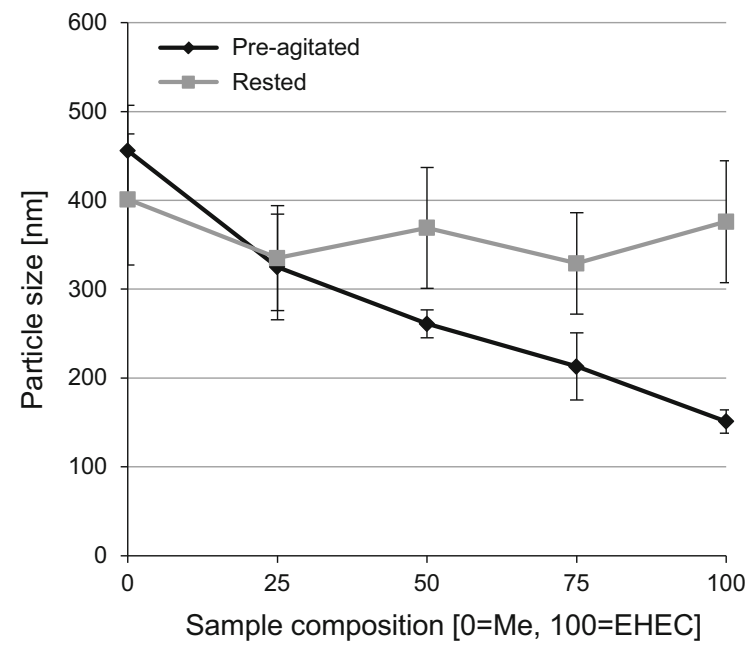

Fig. 6 Particle sizes of EHEC, methyl nanocellulose (Me) and their mixtures were measured at $25^{\circ} \mathrm{C}$ (error bars $95 \%$ confidence interval)

than that of pre-agitated sample, confirming selfassociation and molecular interaction rather than the aggregation of large flocs. In the case of the methyl nanocellulose suspension, the particle size decreased $14 \%$, although the change was statistically insignificant. This could also be explained by the increase in birefringence, which is characteristic of individual cellulose nanocrystals (Parker et al. 2018).

The increase in EHEC particle size at rest is due self-association of the polymer. The association was apparently weak, since the particle size decreased significantly after stirring. The particle sizes of EHEC and methyl nanocellulose at rest were similar. No obvious trend in particle size was observed when the sample composition was changed at rest, but in the stirred sample, the particle size was decreased linearly when the composition was changed towards EHEC.

The particle size distribution of the recently stirred samples shown in Fig. 6 indicates the same phenomenon as in Fig. 7, replacing the nanocellulose with the EHEC reduced the sample particle size when the sample was stirred prior to measurement, but the size distribution was bimodal, and in the ease of E25:Me75 a trimodal distribution was observed. In addition, the sample consisting of EHEC and the nanocellulose compositions had a narrower main peak than the pure samples. The E50:Me50 peak was especially narrow in comparison with the other peaks. The polydispersity indices from cumulant fits showed the same order of relative widths for the distributions. The narrower particle size distributions were thought to indicate an interaction between the nanocellulose and the EHEC.

When samples at rest were heated, no significant change in particle size was observed up to a temperature of $40{ }^{\circ} \mathrm{C}$, at which the EHEC was beginning to show an increase in particle size (Fig. 8). At $50{ }^{\circ} \mathrm{C}$, the sedimentation of EHEC made the sample unsuitable for the measurement. For E75:Me25, the development of sedimentation was similar but less pronounced. In the cloud point measurement of the samples containing methyl nanocellulose, a significant increase in turbidity was found after $50{ }^{\circ} \mathrm{C}$.
Fig. 7 Particle size distribution of EHEC, methyl nanocellulose and their compositions at $25^{\circ} \mathrm{C}$

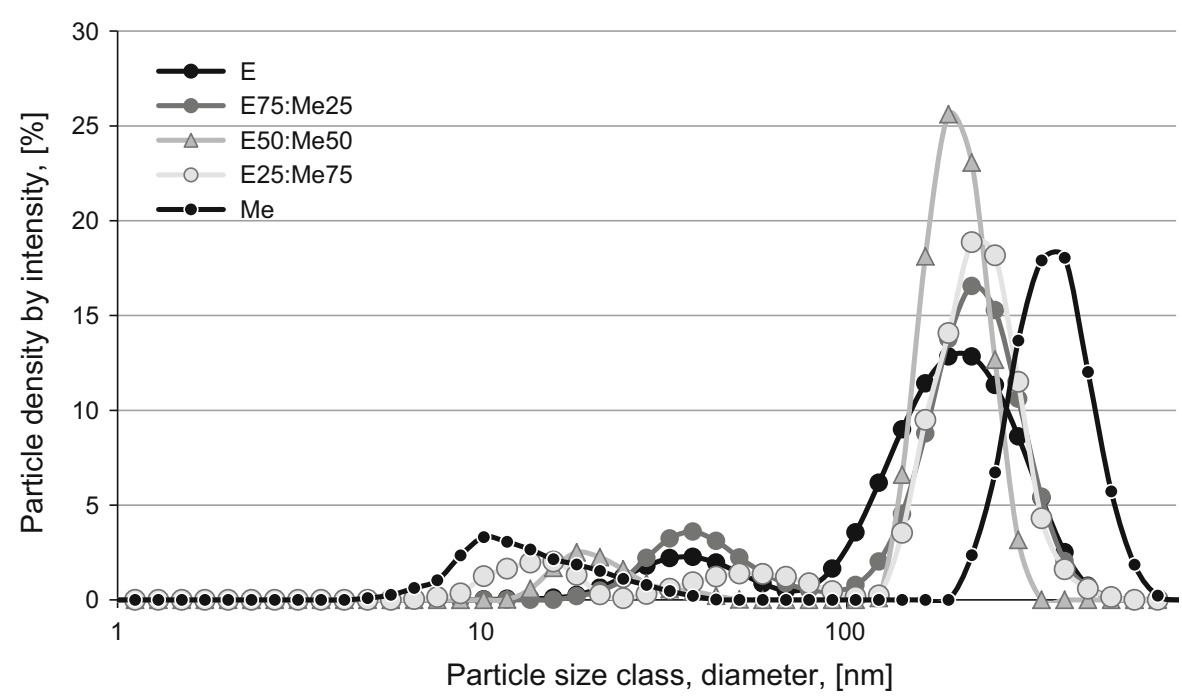




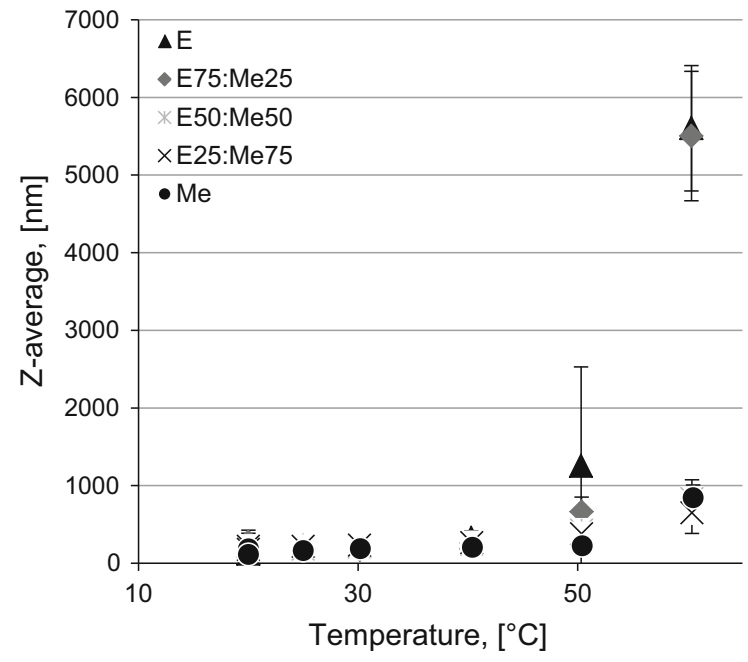

Fig. 8 Particle sizes of the EHEC-methyl nanocellulose mixtures at different temperatures

The methyl nanocellulose solution, on the other hand, showed a different behavior compered to EHEC solutions. Although, methyl nanocellulose showed a clear cloud point at $45^{\circ} \mathrm{C}$, no change in particle size was observed even at a temperature of $50{ }^{\circ} \mathrm{C}$. The concentration may have been too dilute to observe the cloud point, since the cloud point temperature decreases when the concentration is reduced. An increase in average scattering intensity at $40-50{ }^{\circ} \mathrm{C}$ without any increase in particle size indicates a change in particle concentration in the sample or a change in the optical properties. The relatively small particle size, also observed for E25:Me75 and E50:Me50 even at temperature of $60{ }^{\circ} \mathrm{C}$, could partially explain the lack of phase separation of samples consisting both EHEC and methyl nanocellulose.

\section{Conclusions}

The temperature-dependent interaction between hydrophobically modified EHEC and methyl nanocellulose has been determined. An increase in concentration of methyl nanocellulose lowered the gelation and cloud point temperatures of the solution, but in the case of the EHEC-methyl nanocellulose solutions the cloud point temperature increased with increasing content of methyl nanocellulose and the cloud point of EHEC25:Me75 solution was higher than the cloud point of pure methyl nanocellulose solution. The turbidity measurements confirmed that the turbidity started to increase rapidly above the cloud point temperature with increasing addition of methyl nanocellulose.

Oscillatory measurements showed that pure and 75\% methyl-nanocellulose-containing solutions behaved similarly when heated. The gel point temperatures were also similar, although the $75 \%$ nanocellulose-containing mixture was more elastic at the gel point temperature. The $75 \%$ nanocellulosecontaining mixture also showed a higher initial viscosity value than the pure EHEC solution, which indicates the association of EHEC and methyl nanocellulose. Interestingly, the loss modulus value of methyl nanocellulose had a sharp drop before the gelation of the solution started. In addition, both the turbidity and oscillatory measurements revealed that the turbidity and loss modulus G" decrease up to $40{ }^{\circ} \mathrm{C}$ and then start to increase. The increasing turbidity while heating observed with pure EHEC and methyl nanocellulose solutions is due to the decrease in solubility of the compounds in the solution.

The particle size distribution was bimodal for the pure solutions, whereas the E75:Me25 had a trimodal size distribution. The particle sizes of EHEC and methyl nanocellulose were found similar at rest, however, after stirring the particle size of EHEC decreased indicating a weak association of the polymer. Only pure EHEC and E75:Me25 showed a significant increase in particle size when the solutions were heated. Instead, the methyl nanocellulose showed a change in the number of particles with increasing temperature.

Acknowledgments Open access funding provided by LUT University. Stora Enso Oyj is thanked for financial support of the Project. Dr. Anthony Bristow is kindly thanked for the linguistic revision.

Open Access This article is distributed under the terms of the Creative Commons Attribution 4.0 International License (http:// creativecommons.org/licenses/by/4.0/), which permits unrestricted use, distribution, and reproduction in any medium, provided you give appropriate credit to the original author(s) and the source, provide a link to the Creative Commons license, and indicate if changes were made. 


\section{References}

Arvidson SA, Lott JR, McAllister JW, Zhang J, Bates FS, Lodge TP, Sammler RL, Li Y, Brackhagen M (2013) Interplay of phase separation and thermoreversible gelation in aqueous methylcellulose solutions. Macromolecules 46(1):300-309

Carlsson A, Karlström G, Lindman B (1986) Synergistic surfactant-electrolyte effect in polymer solutions. Langmuir 2(4):536-537

Fairclough JPA, Yu H, Kelly O, Ryan AJ, Sammler RL, Radler M (2012) Interplay between gelation and phase separation in aqueous solutions of methylcellulose and hydroxypropylmethylcellulose. Langmuir 28(28):10551-10557. https://doi.org/10.1021/la300971r

Jin W (2017) Preparation of modified nanocellulose and its derivatives. Patent WO2017075417A1

Joabsson F, Rosén O, Thuresson K, Piculell L, Lindman B (1998) Phase behavior of a "clouding" nonionic polymer in water: effects of hydrophobic modification and added surfactant on phase compositions. J Phys Chem B 102(16):2954-2959

Kamitakahara H, Yoshinaga A, Aono H, Nakatsubo F, Klemm D, Burchard W (2008) New approach to unravel the structure-property relationship on methylcellulose, Selfassembly of amphiphilic block-like methylated cellooligosaccharides. Cellulose 15(6):797-801. https://doi.org/ 10.1007/s10570-008-9232-6

Khuman P, Singh WBK, Dushila SD, Naorem H (2014) Viscosity-temperature behavior of hydroxypropyl cellulose solution in presence of an electrolyte or a surfactant: a convenient method to determine the cloud point of polymer solutions. J Macromol Sci Pure Appl Chem 51(11):924-930. https://doi.org/10.1080/10601325.2014. 953377

Kjøniksen AL, Nyström B, Lindman B (1998) Dynamic viscoelasticity of gelling and nongelling aqueous mixtures of ethyl(hydroxyethyl)cellulose and an ionic surfactant. Macromolecules 31(6):1852-1858

Lott JR, McAllister JW, Arvidson SA, Bates FS, Lodge TP (2013) Fibrillar sturcture of methylcellulose hydrogels. Biomacromol 14(8):2484-2488. https://doi.org/10.1021/ bm400694r

McKee JR, Hietala S, Seitsonen J, Laine J, Kontturi E, Ikkala O (2014) Thermoresponsive nanocellulose hydrogels with tunable mechanical properties. ACS Macro Lett 3(3):266-270. https://doi.org/10.1021/mz400596g

Nyström B, Thuresson K, Lindman B (1995) Rheological and dynamic light-scattering studies on aqueous solutions of a hydrophobically modified nonionic cellulose ether and its unmodified analogue. Langmuir 11(6):1994-2002

Nyström B, Kjøniksen AL, Lindman B (1996) Effects of temperature, surfactant, and salt on the rheological behavior in semidilute aqueous systems of a nonionic cellulose ether. Langmuir 12(13):3233-3240

Olsson M, Boström G, Karlson L, Piculell L (2005) Added surfactant can change the phase behavior of aqueous polymer-particle mixtures. Langmuir 21(7):2743-2749

Orts WJ, Godbout L, Marchessault RH, Revol JF (1998) Enhanced ordering of liquid crystalline suspensions of cellulose microfibrils: a small angle neutron scattering study. Macromolecules 31(17):5717-5725

Parker RM, Guidetti G, Williams CA, Zhao T, Narkevicius A, Vignolini S, Frka-Petesic B (2018) The self-assembly of cellulose nanocrystals: hierarchical design of visual appearance. Adv Mater. https://doi.org/10.1002/adma. 201704477

Piculell L, Guillemet F, Thuresson K, Shubin V, Ericsson O (1996) Binding of surfactants to hydrophobically modified polymers. Adv Colloid Interface Sci 63(8):1-21

Tardy BL, Yokota S, Ago M, Xiang W, Kondo T, Bordes R, Rojas OJ (2017) Nanocellulose-surfactant interactions. Curr Opin Colloid Interface Sci 29:57-67. https://doi.org/ 10.1016/j.cocis.2017.02.004

Thuresson K, Lindman B (1997) Effect of hydrophobic modification of a nonionic cellulose derivative on the interaction with surfactants: phase behavior and association. J Phys Chem 101(33):6460-6468

Thuresson K, Nyström B, Wang G, Lindman B (1995) Effect of Surfactant on Structural and thermodynamic properties of aqueous solutions of hydrophobically modified ethyl (hydroxyethyl)cellulose. Langmuir 11(10):3730-3736

Publisher's Note Springer Nature remains neutral with regard to jurisdictional claims in published maps and institutional affiliations. 